\title{
Large scale backfill technology and equipment
}

\author{
P Zhang China ENFI Engineering Corp., China \\ HY Li China ENFI Engineering Corp., China \\ SH Shi China ENFI Engineering Corp., China
}

\begin{abstract}
In recent years, a number of large scale and deep underground metal mines have been developed in China, with proposed annual capacity generally exceeding 10 million tonnes. Where protecting the environment from surface subsidence, optimising recovery of ore resources and reducing the tailings storage requirements, the recommended approach is to fill with tailings backfill. Therefore, the study of large scale backfill technology and corresponding equipment becomes essential. Filling systems with tailings face new technical problems and challenges in large scale backfilling situations.
\end{abstract}

This paper analyses the characteristics of technical processes, strategy selection and organisation of production for large scale backfill. It briefly introduces the paste thickeners and new sand bins, both of which can produce high-density tailings or paste in large quantities. The enlargement and improvement of mechanical mixers of vertical and horizontal types, which are used to mix tailings or paste with binders or other materials, is studied in this paper. A case study using large vertical mixers for backfill is described. The paper then describes the development of pumps for backfill in large flow and high pressure situations. Large scale backfill makes pipeline design critical, and this is also discussed in the paper.

\section{Introduction}

Tailings backfill is a technology where high density tailings or pastes are prepared for filling underground voids, for the purpose of either disposal, or to perform some engineering function (Jewell \& Fourie 2006). Filling systems with tailings usually consist in thickening and dewatering tailings, mixing and preparing the slurries, piping the slurries by gravity or with pumps.

In recent years, a number of large scale and deep underground metal mines have been found in China, with proposed annual capacity generally exceeding 10 million tonnes. In order to protect the environment from surface subsidence, optimise recovery of ore resources and reduce the tailings storage requirements, the recommended approach is to fill with tailings backfill. Therefore, the study of large scale backfill technology and corresponding equipment becomes essential. Filling systems with tailings face new technical problems and challenges in large scale backfilling situation.

\section{$2 \quad$ Large scale backfill technology}

\subsection{Strategies for large scale backfill systems with tailings}

As mentioned previously, filling systems with tailings can usually be divided into three main parts; thickening and dewatering tailings, mixing and preparing the slurries, pipeline transporting by gravity or with the use of pumps. For large scale backfill situations, the technical process is similar, and two strategies may be applied. One strategy is to keep the production of single backfill system unchanged and increase the number of systems, the other is to increase the capacity of the single backfill system. Both strategies have their own advantages and disadvantages.

The advantages of the first strategy include the use of proven and reliable equipment, management experience, lower risk, however the large number of systems require more workers and managers, higher probability of malfunction and larger plant floor area. The second strategy relies on a small number of 
systems, relatively simple management, high execution efficiency, fewer people and less floor space, assuming that new equipment suitable to large scale backfill becomes available. However, the research, design and manufacture of new equipment take time and money, and certain risk may occur during these processes.

Which strategy should be adopted depends on several factors, such as the mining methods recommended, area of project covered, and owner preference. As to large scale and deep underground metal mines, if rock mechanics properties permit, open stoping with delayed backfill method is often suggested in order to obtain a high production rate. In such cases long time continuous backfill operations are required, where single filling system with large capacity is more suitable.

Based on these considerations, this paper will mainly discuss the second strategy for large scale backfill technology, in which new high capacity equipment becomes the key component.

\subsection{Characteristics of large scale backfill using tailings}

The characteristics of large scale backfill using tailings are listed as follows:

- Tailings thickening and dewatering equipment with high handling capacity.

- Thickeners with several hours of tailings storage capacity for either underground or surface disposal.

- Mixing equipment (vertical and horizontal types) with a large capacity for mixing and preparing high-density slurry or paste.

- Large flow and high pressure pumps for pipeline transportation.

- High demand requirements of filling system.

- Good production organisation and management of tailings output and disposal.

- Critical pipeline design for transportation.

The following chapters will focus on the equipment used for large scale backfill operations, especially the mixers.

\section{$3 \quad$ Tailings thickening and dewatering equipment}

Tailings thickening and dewatering equipment play a very important role in the backfill systems using classified tailings or total tailings. There are various types and styles of thickeners, filters, and combination of thickeners and filters, which can generate high-density tailings or paste. For large scale filling system, it often requires thickening the tailings to a high concentration without subsequent operations such as filtration in order to simplify the process, ensure efficiency and lower the costs. Filters of different types are beyond the scope of this paper. This paper will briefly cover the paste thickeners and new sand bins, both of which capable of producing high-density tailings or paste in large quantities.

\subsection{Paste thickener}

In recent years, thickening technology has grown rapidly and high rate thickeners and paste thickeners have been successfully used in the mining industry. China ENFI Engineering Corporation (ENFI) introduced the technology of paste thickeners to China for the first time when it designed the backfill system for Huize Lead-Zinc Mine, Yunnan Chihong Zinc \& Germanium Co., Ltd (Yu 2009).

A typical paste thickener has a deep cone which offers a proven system for optimising flocculation and ensures maximum gravity compression of solids. For large scale backfill systems, a paste thickener with a large capacity is required to produce enough high-density tailings or paste underflows. In China, the diameter of the largest deep cone paste thickener is $40 \mathrm{~m}$, and has been used successfully for tailings surface disposal in Wushan Copper Mine, Inner Mongolia. 


\subsection{New sand bin}

Although backfill systems with paste thickener are relatively stable, easy to control and proven technologies, there are a limited number of paste thickeners manufacturers worldwide. Paste thickeners are relatively expensive, which increases the equipment investment and maintenance costs and restricts their applications. At present, there is an urgent need to research and develop new devices for thickening and dewatering tailings which would render the process simple, reliable, low-cost and easy to operate. Many researchers, engineers and companies in China and abroad have made attempts and some progress has been achieved in this area.

Developing and updating conventional vertical sand tank is an important approach worth studying. Canada Centre for Mineral and Energy Technology (CANMET) has designed an apparatus, where high density slurry or paste is produced from mill tailings in a silo which includes a percolation/decantation device for percolating water out of the mill tailings and for decanting the clarified water from atop the settled tailings. In China, ENFI has developed a new sand bin for continuous preparation of high density slurry or paste, which has been used successfully in several metal mines such as Dongguashan Copper Mine (Shi et al. 2010). Compared to paste thickener, the new sand bin is less expansive and has extra tailings storage capacity.

As to large scale backfill systems, new sand bins or similar device should be updated to improve handling ability, such as increasing the volume, designing more than one discharge gates. The research and development of new sand bin for thickening tailings in large quantity is now under way at ENFI.

\section{$4 \quad$ Mixing equipment}

\subsection{Mixers for backfill}

Mixers are widely used equipment in mineral processing plants and metallurgical plants for mixing or reacting and come in various types and styles. However, there are relatively limited forms of mixers used for backfill for the following reasons:

- The concentration of the slurry is quite high, density can reach more than $70 \%$ (solid by weight).

- The materials handled are varied such as classified or total tailings, cements or binders can be added to the mixtures, sand, etc. and the particle size distribution may be rather complex.

- The main function of the mixer is to maintain the solid-liquid suspension.

- The material of impeller and blades should be wear-resistant.

- Baffles are not usually used for energy saving.

Currently, there are two main types of mixers for backfill in China; vertical and horizontal types, depending on whether the mixing shaft is vertical or horizontal. Vertical type mixers are often used to stir high-density tailings slurries and the mixing speed is relatively high, which means the mixers operate in a turbulent flow regime. Horizontal mixers are generally used to stir pastes and they operate in a laminar flow regime.

\subsection{Increasing the size and improvements of mechanical mixers}

Large scale backfill systems require large mixers with high capacity. It is taken for granted that increasing the size of mixers without changing their main structures, should be a feasible and low-risk approach. Though the theories and principles about enlargement of mixers are quite diverse, there are still specific rules to follow. Key points will be covered in subsequent sections.

\subsubsection{Scaling-up principle}

Scaling up is an important part during an industrial development process, which is based on the principle of similarity. The similarities are geometric, kinematic and dynamic. For mixing equipment scale ups, there are 
multiple similar conditions which may have contradictory effects on the process. Therefore the similar conditions that have important effects on production should be identified and met. The scale up process may be grouped into geometric and non-geometric similarities.

Geometric similarities are chosen for enlarging backfill mixers for the following reasons:

- The mixing operation rarely involves chemical reactions or heat transfer.

- The scaling-up factor $\lambda$ is usually small (2-4).

- Based on existing mixers, the main structure of large mixers such as shaft position and impeller type remains the same.

\subsubsection{Scaling-up index}

The key parameters of large mixers; diameter, height, impeller diameter and other physical dimensions, can be determined by the scaling-up of available small mixers. Therefore, the main question should be at what speed the large mixer needs to rotate in order to have the same stirring effect of the small mixer. In other words, the scale-up index $\beta$ should be determined by:

$$
\left(N_{L} / N_{S}\right) \propto\left(D_{L} / D_{S}\right)^{-\beta}
$$

Where:

$$
\begin{aligned}
& N_{L}=\text { rotating speed of large mixer. } \\
& N_{S}=\text { rotating speed of small mixer. } \\
& D_{L}=\text { diameter of large mixer. } \\
& D_{S}=\text { diameter of small mixer. }
\end{aligned}
$$

The scale-up index $\beta$ varies depending on a constant which is kept unchanged during the enlarging process. Many physical parameters such as Reynolds number Re, power per unit volume $P_{v}$, linear velocity of blade $N_{d}$, etc. may be chosen as the scale-up constant. The operating mechanisms of mixers are complex and the selection of the constant is mostly based on experience.

The main function of mixers for backfill is to maintain the solid-liquid mixture into suspension, where $P_{v}$ can be the constant. For vertical mixers with turbulent flow, the corresponding scale-up index $\beta$ is $2 / 3$. For horizontal mixers with laminar flow, the corresponding index $\beta$ is zero. The rotating speed of large mixer can be derived from Equation (1).

For conditions where the power per unit volume $\mathrm{P}_{\mathrm{v}}$ is the same during the scale-up process, the scaled relationship of mixing power is given by:

$$
P_{L}=\left(D_{L} / D_{S}\right)^{3} \times P_{S}
$$

Where:

$$
\begin{aligned}
& P_{L} \quad=\text { mixing power of large mixer. } \\
& P_{S} \quad=\text { mixing power of small mixer. }
\end{aligned}
$$

\subsubsection{Mechanical design}

Physical dimensions, rotating speed and mixing power of large mixers are obtained as per the aforementioned equations, and the mechanical design can be carried out subsequently. After construction, experimentation and improvements, a mixer with a larger capacity will result. 


\subsection{Case study}

A new large scale backfill systems designed by ENFI for Jinchuan Nickel Mine in China required the doubling of the capacity of the mixers. Thus a scale-up factor of $\lambda=2$ was chosen.

\subsubsection{Parameters of existing mixer}

The parameters of the existing vertical type are: diameter $2,000 \mathrm{~mm}$, height $2,100 \mathrm{~mm}$, impeller diameter $650 \mathrm{~mm}$, rotating speed $242.5 \mathrm{rpm}$, motor power $45 \mathrm{~kW}$, capable of handling $80 \mathrm{~m}^{3} / \mathrm{h}$.

\subsubsection{Parameters of a new large mixer}

The linear ratio of geometrical similarity $\alpha$ is:

$$
\alpha=\lambda^{1 / 3}
$$

The physical dimensions of the large mixer then can be calculated; diameter 2,600 mm, height 3,000 mm, impeller diameter $850 \mathrm{~mm}$.

Choosing $\mathrm{P}_{\mathrm{v}}$ as the scale-up constant, the rotating speed and mixing power can be calculated from Equations (1) and (2): rotating speed $200 \mathrm{rpm}$, motor power $90 \mathrm{~kW}$.

\subsubsection{Industrial testing of a new large mixer}

Following the mechanical design, the new large mixer was manufactured and put to the test. The tests results showed that the preparation of backfill mixtures was feasible and effective (Figures 1 and 2).

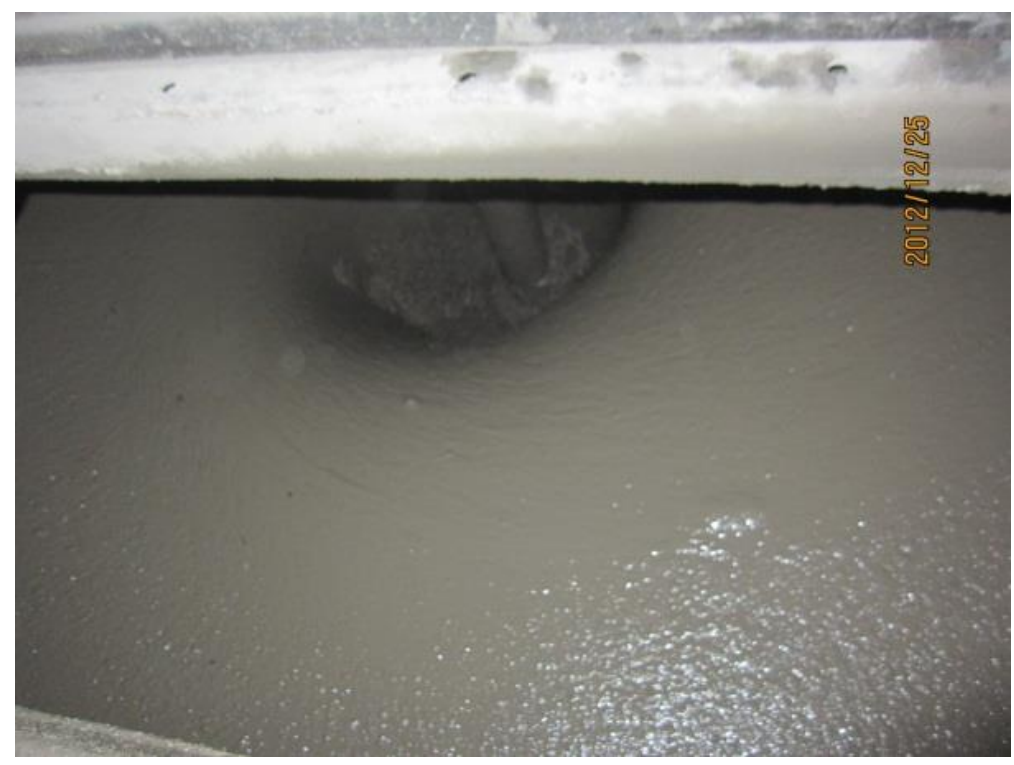

Figure 1 Mixing high-density slurry composed of sand $(-3 \mathrm{~mm})$, cement and water 


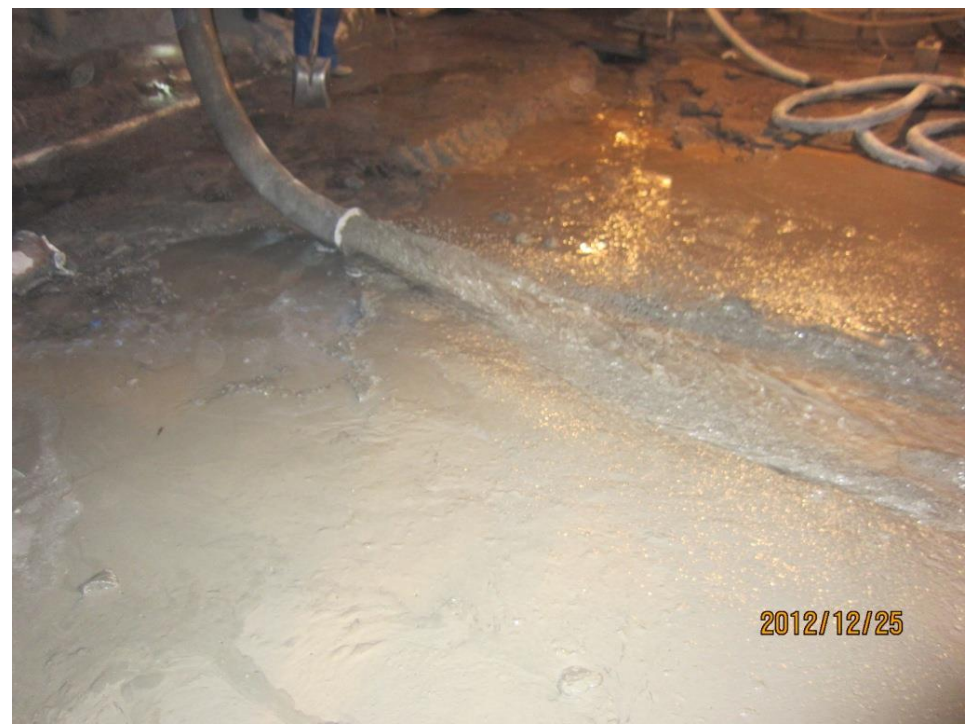

Figure 2 Slurry discharged from the bottom of a large mixer

\section{$5 \quad$ Pumping equipment}

Pumping equipment is usually used to transport high-density slurry or paste mixtures for either backfill or tailings surface disposal because of high pipeline pressure gradients. Positive displacement pumps instead of centrifugal pumps are generally used in such situations.

Piston pumps with large flows and capable of generating high pressures are required for large scale filling system with long pipelines. The pumps should have the ability to work continuously for dozens of hours or several days in order to fill big open stopes. Therefore, the overflow parts of pump should be wear-resistant and capable of high heat dissipation.

All of those pose tough challenges for pump manufacturers.

\section{$6 \quad$ Pipeline transportation}

The design of pipeline transportation for large scale filling systems is critical and the following factors should be considered:

- Selecting the pipe diameter by overall consideration such as pump selection, installation and maintenance costs.

- Selecting pipeline materiel that is wear-resistant and light.

- Using computer simulation technology instead of pipe-loop-tests to estimate pipeline pressure gradients.

\section{Conclusions}

In recent years, the emergence of large scale and deep underground metal mines in China and abroad reinforces the need for studying and designing large scale backfill technologies and equipment. This paper analyses the strategies for selecting and designing large scale backfill equipment. It focuses on the equipment used for large scale backfilling, including paste thickeners and new sand bins capable of handling large tonnages, mixers of large capacity and pumps with large flows and high pressures. Scaling-up of mixers is mainly discussed in this paper and an industrial case using large vertical mixers for backfill is shown.

This paper will offer guidance to engineers, researchers and manufacturers on how to scale-up new backfill equipment from smaller models. 


\section{References}

Jewell, RJ \& Fourie, AB 2006, Paste and Thickened Tailings - A Guide, 2nd edn, Australian Centre for Geomechanics, Perth, Western Australia, pp. 95-116.

Shi, SH, Li, HY \& Chen, HQ 2010, 'Development and innovation of mine backfilling technology', China Mining Engineering, vol. 39, no. 5, pp. 10-3.

Yu, RC 2009, Mining Engineers Handbook, vol. 2, Metallurgical Industry Press, Beijing, pp. 79-95. 
